\title{
Solar assisted heat pump modelling
}

\author{
Denizhan Özenen ${ }^{1 *}$, Mustafa Turhan Çoban ${ }^{1}$ \\ 'Department of Mechanical Engineering, Faculty of Engineering, Ege University, Bornova, İzmir, Turkey
}

Orcid: D. Özenen (0000-0002-3462-4538), M.T. Çoban (0000-0003-1873-2640)

\begin{abstract}
The Solar Energy Assisted Heat Pump (SAHP) system is modeled by creating different processes with the help of various models created in the JAVA program. The SAHP model was created in order to obtain hot water by utilizing solar energy. The inlet water temperature in the system was taken as $10^{\circ} \mathrm{C}$ in December and $20.5^{\circ} \mathrm{C}$ in June and the SAHP model was analyzed by numerical method. In the evaporator model, considering the coordinates of the city of Izmir, various graphs were created by calculating the different spectral solar energy values falling on I m2 evaporator plate on certain days of 2019. In the graphics, the highest energy density on I m2 evaporator plate for Izmir province was $852.095 \mathrm{~W} / \mathrm{m} 2$ on 21 June at 12:00, and the lowest energy density was $455.143 \mathrm{~W} / \mathrm{m} 2$ on 21 December at 12:00. In the SAHP system, the evaporator plate area was determined as $2.40 \mathrm{~m} 2$ and the compressor power was $0.56 \mathrm{~kW}$, and a condenser model was created. The required condenser surface areas were found by calculating the thermal energies given by the condenser for different dates in the system. In the modeling of the heat pump, the Coefficient of Performance (COP) of the SAHP system for RI34a and R404A was obtained by taking the date of June 2I, I2:00, when the spectral energy is most intense, as a reference.
\end{abstract}

Keywords: Solar Energy; Solar Powered Heat Pump; JAVA; Modeling; Energy Efficiency; Performance Analysis

\section{Introduction}

Harmful effects of burning fossil fuels on the global climate occur day by day. Some institutions have aware of this situation increase environmental protection laws in the world. The European continent aims to be the first climate-neutral continent in the world in 2050, especially with the European green agreement signed by the European Union member states. For this important goal, the European Commission has committed to amending existing environmental legislation, which will reduce the emission rate on the continent by $55 \%$ by 2030 [1]. Characteristics of solar energy are intermittence and low density so solar heating has largely been restricted. The solar-assisted heat pump (SAHP) system could be solving the intermittence and low-density solar energy problem. Low-grade thermal energy can be exposed by using SAHP systems. Thus residual heat is useable for applications water heating and space heating, while thermal solar energy must be useful for heating and cooling processes, target utilization areas for solar technologies are those that require low-temperature heat like water heating, space heating, drying process, pool heating, and certain industrial processes [2]. Heat pumps are widely used to upgrade free heat from renewable energy sources and they can provide a dramatic reduction in energy consumption between house utility costs [3]. In the study, solar-assisted evaporator plate modeling was made instead of the fan evaporator which is used as an evaporator in air-assisted heat pump systems. The solar boosted evaporator plate model was aimed to increase the energy efficiency of the heat pump system. In the JAVA program with SAHP model in the heat pump cycle by doing, it has been made an effort to optimize all systems parameters separately.

\section{Material and Methods}

SAHP model were included the energies kept, emitted and absorbed by the plate together with energy coming from the sun, thermodynamic and thermophysical properties of humid air, thermodynamic and thermophysical properties of refrigerants, double pipe heat exchanger features, Heat pump-refrigeration cycle. As a results of the data outputs of the program various solar energy graphs, JAVA data outputs, evaporate plate heat capacity, condenser heat capacity and condenser area tables have demonstrated for İzmir city.

\section{I. Mathematical Models}

SAHP regions were analyzed by making to solving the mathematical expressions of the energy balance equations of each region with the created JAVA models. As shown in Figure 1, The SAHP system cycle takes place in five main components namely: compressor, condenser (double pipe heat exchanger), expansion valve, evaparatör plate and water storage. 


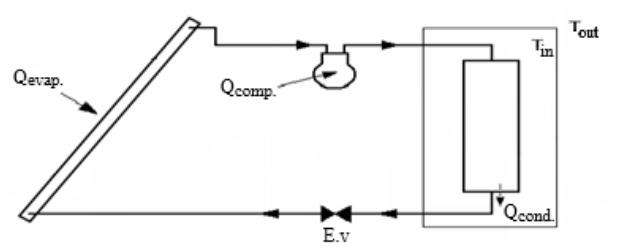

Qevap. $=$ Solar energy coming to the evaporator plate

$Q_{\text {comp. }}=$ Energy produced by the compressor

$Q_{\text {cond. }}=$ Energy coming in
E.v

Figure I. Basic SAHP system cycle

\subsection{Solar Radiation model}

The availability of very high altitude aircraft, balloons, and spacecraft have permitted direct measurements of solar radiation outside most or all of the earth's atmosphere. These measurements were made with a variety of instruments in nine separate experimental programs. They resulted in a value of the solar constant $G_{s c}(\lambda)$ of $1353 \mathrm{~W} /$ $\mathrm{m}^{2}$ with an estimated error of $\pm 1.5 \%$ [ 4 ]. The function values of the wavelength of the sun's extraterrestrial solar radiation values between $0.25 \lambda \mu \mathrm{m}$ and $8 \lambda \mu \mathrm{m}$ were taken into consideration. The cubic strip curve formulas are benefitted by utilize these function values of the wavelength in model. To construct our model, we need to calculate the spectral energy density $G(\lambda)$ falling on the earth horizontal surface. In the Equation $1 G(\lambda), G_{s c}(\lambda)$ is the spectral amount of solar energy, $\mathrm{n}$ is the day of the year, and $\theta_{z}$ zenith angle.

$$
G(\lambda)=G_{s c}(\lambda)\left(1+0.0333 \cos \left(\frac{360 n}{365}\right)\right) \cos \left(\theta_{z}\right)_{\tau}
$$

Considering that the energy absorbed by the surface is equal to the energy emitted by the surface according to Kirchhoff's law; directional-spectral emissivity $\left(\varepsilon_{\lambda}\right)=$ directional-spectral absorptivity $\left(\rho_{\lambda}\right)[5]$. Directional-spectral emissivity coefficients $\left(\varepsilon_{\lambda}\right)$ of a nickel-plated copper selective surface plate were converted to function form using the cubic strip interpolation method. For thermal balance, we have to calculate the best emitter of radiation at every wavelength and in every direction for a blackbody using Planck distribution Equation 2.

$$
E_{\lambda, b}(\lambda, T)=\frac{2 \pi h c_{0}^{2}}{n^{2} \lambda^{5}\left[\exp \left(h c_{0} /(n \lambda k T)-1\right)\right]}
$$

\subsection{Evaporator finite difference method model}

It is assumed that the outside air is humid and its temperature does not change at the evaporator model. The evaporator plate is modeled as a flat plate located in a horizontal position, and by creating finite differences for our model, the energy input for each finite-difference step and the refrigerant enthalpy change at each step was calculated according to the following Equations 3 - 4 .

$$
\begin{aligned}
& d Q=d A\left(q_{A b s o r b e d}-q_{\text {Radiated }}+q_{\text {Natural Con. } .}\right) \\
& H_{j+1}=H_{j}+d H_{j}=H_{j}+d Q / m_{j}
\end{aligned}
$$

\subsection{Condenser finite difference method model}

In the condenser model, the finite difference model is mainly applied. Since the condenser is a phase-shifting heat exchanger, enthalpy steps are used as finite difference steps. By comparing the enthalpy values with the saturation zone gas and liquid enthalpies, the phase region we are in is found. Thus temperature profiles, pressure drop and heat transfer calculations are performed. Heat transfer for tube and enthalpy change step was calculated according to following Equations 5 - 6 .

$$
\begin{aligned}
& d q_{j}=U_{i-j} d A_{i-j} T_{0-i}-T_{i-j} \\
& d H_{j}=\frac{d H_{j}}{m_{j}} \text { and } H_{j+1}=H_{j}-d H_{j}
\end{aligned}
$$

\subsection{Compressor and Expansion valve model}

In the heat pump model designed have been referenced the Embraco NEU2168GK model $(0.75 \mathrm{hp}=0.56 \mathrm{~kW}=560$ Watt), which can use R134a gas. The fluid enthalpy at the inlet and outlet of the expansion valve was accepted as constant and the following orifice Equation 7 specified in James and James (1987) was used in the modeling of the valve.

$$
\dot{m}=0.00683 x \sqrt{P_{\text {cond }}-P_{\text {evap }}}
$$

\subsection{Evaporative natural convection heat transfers}

The evaporator is designed basically like a flat plate. In addition to the energy coming from the sun to the evaporator plate, it is also being energy transfer from the air by natural convection and advection thus Nusslet correlations are used for heat flow in natural convection energy transfer. Natural convection energy transfer can be calculated with the following formula in Equation 8.

$$
Q=h\left(T_{s}-T_{\infty}\right) W / m^{2}
$$

\subsection{Thermodynamic and thermophysical properties of wet air properties}

In the numerical model, all thermodynamic properties are calculated using the Specific Helmholtz free energy of humid air at following Equation 9 by taking wet air as the real gas for the outside air [6].

$$
\begin{aligned}
& f^{A V}(A, T, \rho)=(1-A) f^{V}\left(T, \rho^{V}\right) \\
& +A f^{A}\left(T, \rho^{A}\right)+f^{\text {mix }}(A, T, \rho)
\end{aligned}
$$

\subsection{Thermodynamic properties of refrigerants}

When modeling the evaporator and condenser, refrigerant 
flows through the pipe. Therefore, we also need thermodynamic and thermophysical models of the refrigerant. For this modeling, the Helmholtz free energy dimensionless form equation is used as the standard ground state equation (The International Association for the Properties of Water and Steam-IAPWS) [7]. This Equation 10 for pure refrigerants:

$$
\phi=\frac{A}{R T}=\phi_{i d}(\rho, T)+\phi_{r}(\rho, T)
$$

\subsection{Single and double phase heat exchange formulas of refrigerants}

To get the following Equation 11 boiling heat transfer coefficient $\left(h_{t p}\right)$ for R134a, the convective-boiling term $\left(h_{c b}\right)$ and the nucleate-boiling term $\left(\mathrm{h}_{\mathrm{nb}}\right)$ has used. These terms include a various parameters and correlations.

$$
h_{t p}=\sqrt{h_{c b}^{2}+h_{n b}^{2}}
$$

\section{Results}

\section{I. Solar Assisted Heat Pump Cycle Model}

As shown in Figure 2 by creating a function graph of the atmospheric spectral energy density of solar rays in the wavelength range of 0.25 to 8 micrometers specified wavelength range, we have reached the value of $1353.9 \mathrm{~W}$ $/ \mathrm{m} 2 \mu \mathrm{m}$ from the cubic strip formulas. In JAVA, spectral emissivity $\varepsilon(\lambda)$ values of Nickel-plated copper selective surface were converted to function form with cubic strip interpolation algorithm.

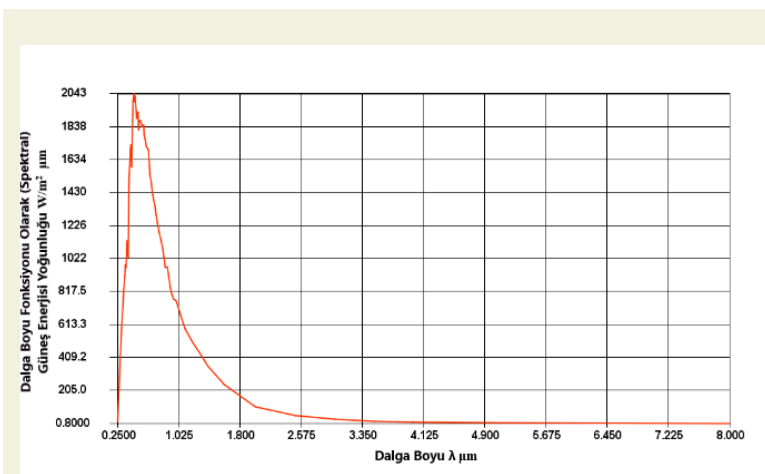

Figure 2. Extraterrestrial solar radiation of 0.25 to 8 micrometers with cubic strip interpolation formula

It has been determined that the solar radiation was a change for Photovoltaic/Thermal-Solar Assisted Heat Pump (PV/T-SAHP) between $300 \mathrm{~W} / \mathrm{m}^{2}$ and $1000 \mathrm{~W} /$ $\mathrm{m}^{2}$ [8]. İn the study by doing the 2019 spectral analyze of solar energy intensity for the city of Izmir has been determined between $400 \mathrm{~W} / \mathrm{m}^{2}$ and $900 \mathrm{~W} / \mathrm{m}^{2}$. According to spectral solar energy functions at Figure 3, it is striking that the amount of energy density per $1 \mathrm{~m}^{2}$ evaporator plate is the lowest on December 21 and the highest on June $21.1 \mathrm{~m}^{2}$ nickel-plated copper type plate used as evaporator surface with the integration values of the cubic strip algorithm of spectral data; For the date of 21 December 2019, the amount of energy falling on the evaporator plate was $455.143 \mathrm{~W} / \mathrm{m}^{2}$, the energy absorbed in the plate was $388.508 \mathrm{~W} / \mathrm{m}^{2}$ and the radiation emitted from the plate was obtained as $60.307 \mathrm{~W} / \mathrm{m}^{2}$. On 21 June 2019 the energy amount falling on the evaporator plate was $852.095 \mathrm{~W} / \mathrm{m}^{2}$, the energy absorbed in the plate is $727.344 \mathrm{~W} / \mathrm{m}^{2}$ and the radiation emitted from the plate is as $112.904 \mathrm{~W} / \mathrm{m}^{2}$.

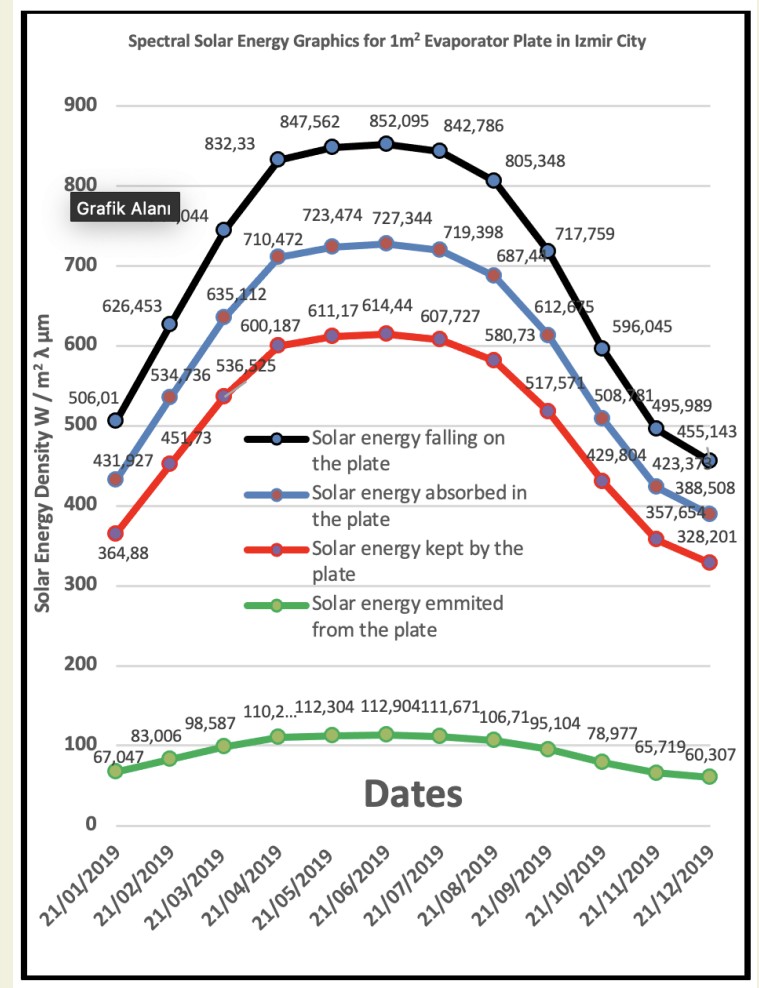

Figure 3. The annual graph of the spectral solar energy absorbed by the $1 \mathrm{~m}^{2}$ evaporator plate

\subsection{Solar-Boosted Evaporator Plate Model Results}

21 December 2019 and 21 June 2019 were taken as reference for the heat energy required for the evaporator plate in the Java program data output. The amount of energy absorbed and reflected in the $2.40 \mathrm{~m}^{2}$ evaporator plate at the dates determined in the analysis is shown in Table 1.

Table I. Solar Absorption in $2.40 \mathrm{~m} 2$ Evaporator Plate of Two Different Date

$\begin{array}{ccc}\text { Evaporator Plate Area } & \text { 21 December 2019 } & \text { 21 June 2019 } \\ 2.40 \mathrm{~m}^{2} & \text { 787.682 Watt } & 1.474 .656 \text { Watt }\end{array}$

\subsection{Double Pipe Reverse Parallel Flow Condenser Model Results}

The condenser thermal capacity is obtained according to this following Equation 12 and in Table 1, the sum of the 
solar energy obtained in the $2.40 \mathrm{~m} 2$ evaporator plate and the 560watt energy from compressor is shown in Table 2.

$$
Q_{\text {condenser }}=W_{\text {comp }}+Q_{\text {evaporator }}
$$

Table 2.The Heat from the Condenser at Different Dates
$\begin{array}{ccc}\text { Dates } & \text { 21 December 2019 } & \text { 21 June 2019 } \\ \text { Heat From Condenser } & \text { 1.347.682 Watt } & \text { 2034.656 Watt }\end{array}$

In the finite difference model of the condenser, the heat transfer coefficient $(U)$ term varies as a function of the mass velocity is changed at each step by using Equation 13 for the surface heat transfer flowing by heat transfer. In order to determine in which phase region the refrigerant is in the condenser model, the heat transfer rate Equations 5 within the pipe is compared with the enthalpy steps Equations 6.

$$
\Delta Q i=U i(T h i, T c \mathrm{i}, m \mathrm{~h}, m c, D \mathrm{~h}, D c, \varepsilon \mathrm{h}, \varepsilon c) \Delta A i[T \mathrm{hi}-T c]
$$

In JAVA, pressure and sudden contractions losses for flow in and out the pipe are neglected, the inlet temperature of the refrigerant was determined to be $52^{\circ} \mathrm{C}$ by using $\mathrm{R} 134 \mathrm{a}$ and R404A gas as the refrigerant. Taking as reference the monthly average water temperatures of Izmir shown in Table 3. was set the temperature of the water entering the condensers, respectively $10^{\circ} \mathrm{C}$ on 21 December 2019 and $20.5^{\circ} \mathrm{C}$ on 21 June 2019 . Thus, the surface area of the required condenser areas was calculated by making

\begin{tabular}{|c|c|c|}
\hline Dates & 21 December 2019 & 21 June 2019 \\
\hline $\mathrm{Q}_{\text {condenser }}$ & 1353.156 Watt & 2056.5 I 8 Watt \\
\hline$\dot{\boldsymbol{m}} \mathrm{RI} 34 \mathrm{a}$ & $0.01 \mathrm{~kg} / \mathrm{s}$ & $0.01 \mathrm{~kg} / \mathrm{s}$ \\
\hline$\dot{\boldsymbol{m}} \mathrm{H}_{2} \mathrm{O}$ & $0.02 \mathrm{~kg} / \mathrm{s}$ & $0.02 \mathrm{~kg} / \mathrm{s}$ \\
\hline $\mathrm{T}_{\mathrm{H} 2 \mathrm{O} \text { inlet }}$ & $10^{\circ} \mathrm{C}$ & $20.5^{\circ} \mathrm{C}$ \\
\hline$T_{\text {R314a inlet }}$ & $52{ }^{\circ} \mathrm{C}$ & $52{ }^{\circ} \mathrm{C}$ \\
\hline$T_{\text {H2O outlet }}$ & $12.38^{\circ} \mathrm{C}$ & $22.98^{\circ} \mathrm{C}$ \\
\hline$T_{\text {R314Aoutlet }}$ & $38.5^{\circ} \mathrm{C}$ & $38.6^{\circ} \mathrm{C}$ \\
\hline Pipe Length (L) & $1.7 \mathrm{~m}$ & $2.1 \mathrm{~m}$ \\
\hline $\begin{array}{c}\text { JAVA Required Conden- } \\
\text { ser Area }\end{array}$ & $0.1353 \mathrm{~m}^{2}$ & $0.2116 \mathrm{~m}^{2}$ \\
\hline
\end{tabular}
water ingresses at different temperatures.

Since the amount of solar energy obtained from the evaporator plate in the SAHP system changes, the amounts of energy obtained in the condenser on December 21 and June 21 also changes. For this reason, different condenser areas are needed in SAHP, the analysis made with different condenser areas are shown in Figure 4 and Figure 5.

\subsection{Solar Assisted Heat Pump Cycle Model}

In the SAHP modeling at JAVA, the spectral energy amount falling on the $2.40 \mathrm{~m} 2$ evaporator plate at the

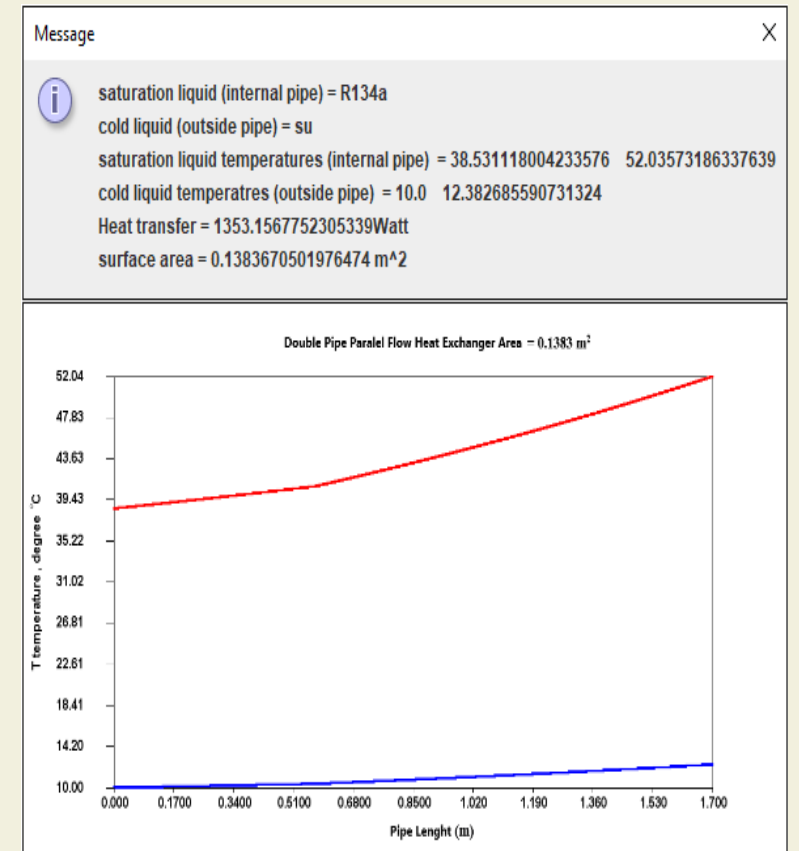

Figure 4. JAVA data output with R134a refrigerant and water temperature change

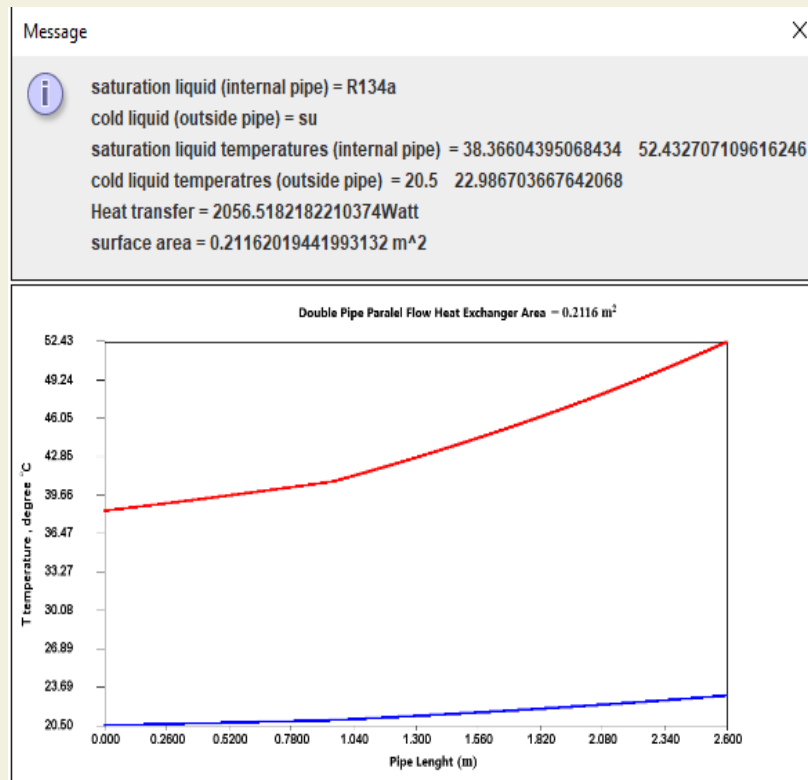

Figure 5. JAVA data output with R134a refrigerant and water temperature change

best solar energy efficiency date 21 June 2019 was taken as a reference. In order to compare the efficiency of refrigerants with different properties, R134a and R404A refrigerants were tested separately in the SAHP system. All data obtained from the cycle regions in the SAHP are given in. In Table 4, when we compare the R134a and $\mathrm{R} 404 \mathrm{~A}$ COP condenser performance $\mathrm{R} 134 \mathrm{a}$ is seen better than R404A.

\section{Discussion and Conclusions}

\section{I. Discussion}

This is the first report of applying JAVA mathematical 
Table 4. JAVA SAHP results.

Ideal refrigeration
cycles
RI34a and R404A
Mass flow rate $\dot{m}$
Water Mass flow rate $\dot{m}$
Condenser heat
output
Evaporator heat input
Compressor work
İsentropic comp. work
COP evaporator
COP condenser
COP evaporator
Carnot
COP condenser
Carnot

$\mathrm{PI}$ compressor input

TI compressor input

hl compressor input

SI compressor input

$X I$ compressor input

P2 compressor output

T2 compressor output

h2 compressor output

S2 compressor output

$\mathrm{X} 2$ compressor output

P3 condenser output

h3 condenser output

T3 condenser output

S3 condenser output

$\mathrm{X} 3$ condenser output

P4 Expansion output

h4 Expansion output

T4 Expansion output

S4 Expansion output

X4 Expansion output

P5 condenser saturation

h5 compressor input

T5 condenser saturation

S5 condenser saturation

X5 condenser saturation

P6 condenser saturation

h6 compressor input

T6 condenser saturation

S6 condenser saturation

$\mathrm{X} 6$ condenser saturation
Capture Output -----------

$\begin{array}{cc}\text { RI34a } & \text { R404A } \\ 0.01 \mathrm{~kg} / \mathrm{s} & 0.01 \mathrm{~kg} / \mathrm{s} \\ 0.02 \mathrm{~kg} / \mathrm{s} & 0.02 \mathrm{~kg} / \mathrm{s} \\ & 1.960730401387 \mathrm{~kW}\end{array}$

$1.488364767200 \mathrm{~kW} \quad 1.409654089724 \mathrm{~kW}$

$0.55464003868 \mathrm{l} \mathrm{kW} \quad 0.551076311663 \mathrm{~kW}$ $0.4437 \mid 20309452$ $\mathrm{kW}$

$0.4408610493305 \mathrm{~kW}$

$2.683478767 / 2 \mathrm{~kW} \quad 2.558001605022 \mathrm{~kW}$

$3.683478767 / 26 \mathrm{~kW} \quad 3.558001605022 \mathrm{~kW}$

$3.346832204799 \mathrm{~kW} \quad 3.3730405454 \mathrm{l} \mathrm{kW}$

$4.34683220479 \mathrm{~kW} \quad 4.373040545417 \mathrm{~kW}$

$200.0 \mathrm{kPa}$

$200.0 \mathrm{kPa}$

$-0.0758453309716$ ${ }^{\circ} \mathrm{C}$

$-20.26999999999^{\circ} \mathrm{C}$

401.1322780063 $\mathrm{kJ} / \mathrm{kg}$

$360.7661939387 \mathrm{~kJ} / \mathrm{kg}$

$1.7651661475 \mathrm{~kJ} / \mathrm{kgK} \quad 1.6717379366 \mathrm{~kJ} / \mathrm{kgK}$

$2.0 \mathrm{kgvapor} / \mathrm{kgtotal} \quad 2.0 \mathrm{kgvapor} / \mathrm{kgtotal}$

$1500.0 \mathrm{kPa}$

$1500.0 \mathrm{kPa}$

$81.5159817936^{\circ} \mathrm{C} \quad 81.5159817936^{\circ} \mathrm{C}$

456.5962818745

$\mathrm{kJ} / \mathrm{kg}$

$415.873825105 \mathrm{~kJ} / \mathrm{kg}$

$1.7968802164 \mathrm{~kJ} / \mathrm{kgK} \quad 1.7052363382 \mathrm{~kJ} / \mathrm{kgK}$

I.2157 kgvapor/

kgtotal

$1.2820 \mathrm{kgvapor} / \mathrm{kgtotal}$

$1500.0 \mathrm{kPa}$

$252.29580 I 2863$

$\mathrm{kJ} / \mathrm{kg}$

$1500.0 \mathrm{kPa}$

$37.23278849288^{\circ} \mathrm{C} \quad 13.93186150339^{\circ} \mathrm{C}$

$1.1774949394 \mathrm{~kJ} / \mathrm{kgK} \quad 1.0696918934 \mathrm{~kJ} / \mathrm{kgK}$

$0.0 \mathrm{kgvapor} / \mathrm{kgtotal} \quad 0.0 \mathrm{kgvapor} / \mathrm{kgtotal}$

$200.0 \mathrm{kPa}$

$200.0 \mathrm{kPa}$

$252.29580 I 2863$

$\mathrm{kJ} / \mathrm{kg}$

$219.8007849663 \mathrm{~kJ} / \mathrm{kg}$

$-10.07584533097^{\circ} \mathrm{C} \quad-30.71847169730^{\circ} \mathrm{C}$

$1.2000130532 \mathrm{~kJ} / \mathrm{kgK} 1.08272783724 \mathrm{~kJ} / \mathrm{kgK}$

$0.0 \mathrm{kgvapor} / \mathrm{kgtotal} \quad 0.0 \mathrm{kgvapor} / \mathrm{kgtotal}$

$1500.0 \mathrm{kPa}$

$1500.0 \mathrm{kPa}$

425.2294878195 $\mathrm{kJ} / \mathrm{kg}$

$378.7405040638 \mathrm{~kJ} / \mathrm{kg}$

$55.23278849288^{\circ} \mathrm{C} \quad 32.300832851^{\circ} \mathrm{C}$

1.704885 I $689 \mathrm{~kJ} / \mathrm{kgK} \quad \mathrm{I} .59 \mid 43720440 \mathrm{~kJ} / \mathrm{kgK}$

$0.0 \mathrm{kgvapor} / \mathrm{kgtotal} \quad 0.0 \mathrm{kgvapor} / \mathrm{kgtotal}$

$1500.0 \mathrm{kPa}$

$1500.0 \mathrm{kPa}$

$279.83987206 \mathrm{~kJ} / \mathrm{kg} \quad 247.0748924 \mathrm{~kJ} / \mathrm{kg}$

$55.23278849288^{\circ} \mathrm{C} \quad 31.93186150339^{\circ} \mathrm{C}$

$1.2621492016 \mathrm{~kJ} /$ $\mathrm{kgK}$

$1.1599026050 \mathrm{~kJ} / \mathrm{kgK}$

$0.0 \mathrm{kgvapor} / \mathrm{kgtotal} \quad 0.0 \mathrm{kgvapor} / \mathrm{kgtotal}$ models to compare the refrigerant R134a and R404A gas in SAHP system the best of knowledge. The main purpose of the SAHP model is to help determine the basic parameters for a prototype to be manufactured. Different experimental models have been made for the SAHP system in different applications. However, there are not many studies on the SAHP system based on mathematical models.

The numerical model created under Kazakhstan climatic conditions is based on energy and mass balance. The numerical simulation was performed between $-30{ }^{\circ} \mathrm{C}$ and $30^{\circ} \mathrm{C}$ with solar intensities between 100 and $900 \mathrm{~W} / \mathrm{m}^{2}$. The numerical simulation results showed that heat pump assisted re-generative solar still has more energy efficiency according to a conventional simple solar still [9]. In the study, four different solar assisted heat pump systems were simulated and the energy and financial status of the systems were evaluated. As a result of the analyzes, it was seen that the PV energy supported air source heat pump heating system was the most financially sustainable system with $0.23 € / \mathrm{kWh}$ electricity cost [10]. In the simulation, using R134a refrigerant in the PV assisted heat pump system, the solar radiation variation in the panel is between $300 \mathrm{w} / \mathrm{m} 2$ and $1000 \mathrm{w} / \mathrm{m} 2$. It was determined that the PV panel of the heat pump system was at a maximum of $35.68{ }^{\circ} \mathrm{C}$ at $14: 00$, and the average COP and $\mathrm{COP}_{c x}$ values were obtained as 6.14 and 1.49 , respectively [11]. In the city of Montreal, Canada, renewable source heat pump systems were installed in houses with an area of 210 $\mathrm{m} 2$, which were built in accordance with the energy-efficient detached house concept of the 1980s. Looking at the houses in general, it is seen that the (Air Sources Heat Pump-ASHP) system has the lowest lifetime cost and energy savings [12]. (Direct Expansion / Solar Assisted Heat Pump-DX/SAHP) system was studied experimentally under the meteorological condition of Qingdao located in the East China, and under the sunny and overcast day conditions in the autumn, the average COP was higher than 4.0 and 3.0, respectively. The average COP value of (DX/SAHP) system was seen higher than 2.5 even in extreme weather of the winter conditions [13].

Experimental or Numerical analyzes of heat pump systems are made in studies. However, generally the operating cost or investment cost of the heat pump systems were focused on. It is extremely important to develop efficiency-based projects in heat pump systems, and together with numerical analysis, it is seen that this is possible with a lower cost.

\subsection{Conclusions}

Parameters to be carried out on the applicable SAHP prototype can be based on the data to be obtained with the JAVA program as in Figure 6. Thus, a faster and lower-cost development process can be created for the SAHP system. Under the data obtained from the studies conducted, it 
is aimed to increase the thermal performance values of the systems by making improvements day by day in the disadvantageous applications in SAHP systems [14]. To analyze the researches on low-temperature heating applications of SAHP systems, basic performance data of SAHP systems were collected and various conventions of these data were compared [15]. All Equations in the SAHP cycle are programmed in JAVA in a computer environment and a typical output of the program is shown in Table 4. When the cycle data of R404A and R134a refrigerants are examined, the COP values of $\mathrm{R} 404 \mathrm{~A}$ and R134a are seen above 3.5 in Table 4. Since the COP condenser performance of the R134a refrigerant in the cycle is better in Table 4. R134a T-s diagram was created for SAHP at JAVA in Figure 6. In the analysis made in the T-s diagram, it is seen that the results obtained from all numerical models made with the algorithms created in the JAVA program are compared and the results are close and consistent with each other.

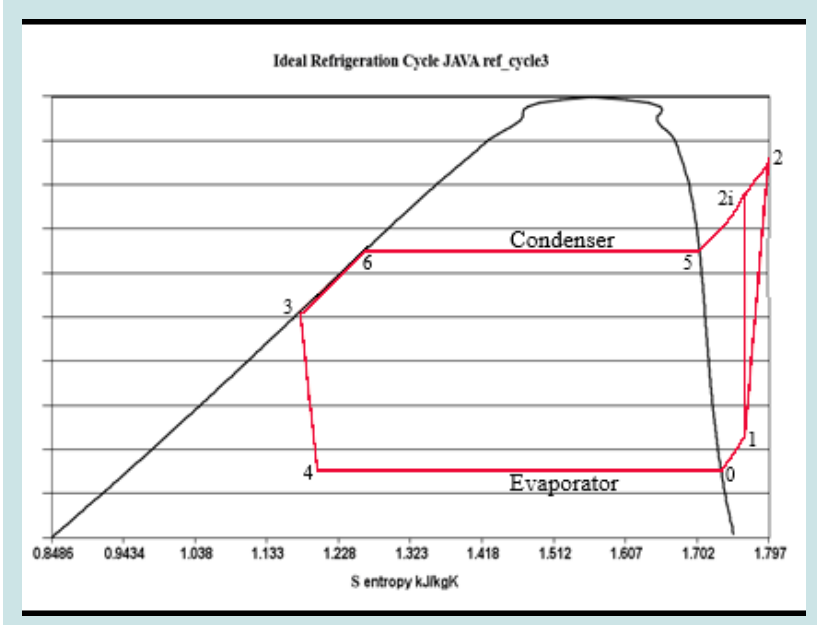

Figure 6. JAVA SAHP R134Aa T-s diagram

\section{Nomenclature}

$G_{s c} \quad$ Solar radiation constant

$\theta_{z} \quad$ Zenith angle

$n \quad$ Day of the year

$\varepsilon_{\lambda} \quad$ Directional-spectral emissivity

$\rho_{\lambda} \quad$ Directional-spectral absorptivity

$E_{\lambda, b} \quad$ Planck's laws distribution

$d Q \quad$ Energy input for each finite-difference

$H_{j+1} \quad$ Refrigerant enthalpy changes at each step

$d q_{j} \quad$ Heat transfer for tube

$d H_{j} \quad$ Enthalpy change step for tube

$\dot{m} \quad$ Orifice Equation

$Q \quad$ Natural convection energy transfer
$f^{A V} \quad$ Specific Helmholtz free energy of humid air

$f^{V} \quad$ Water properties of Specific Helmholtz free energy

$f^{A} \quad$ Dry air properties of Specific Helmholtz free energy

$f^{m i x}$ Air-water cross virial part properties of Specific Helmholtz free energy

A Dry-air mass fraction

$T \quad$ Absolute temperature

$\rho \quad$ Mass density

$R \quad$ Specific gas constant

$\phi \quad$ Helmholtz free energy dimensionless form

$\phi_{i d} \quad$ The ideal-gas part of the dimensionless Helmholtz free energy

$\phi_{r} \quad$ The residual part of the dimensionless Helmholtz free energy

$h_{t p} \quad$ Boiling heat transfer coefficient

$h_{c b} \quad$ Convective-boiling term

$h_{n b} \quad$ Nucleate-boiling term

COP Coefficient of Performance

\section{References}

[1]Renewable energy directive. (2014, July 16). EuropeanCommission:https://ec.europa.eu/energy/topics/renewable-energy/renewable-energy-directive/overview_en

[2] Ioan Sarbu, C. S. (2016, August). Solar Assisted Heat Pump Systems. Renewable Energy, 79-129. doi:10.1016/B978-0-12811662-3.00009-8

[3] Martin Kegel, J. T. (2012, December). Assessment of a solar assisted air source and a solar assisted water source heat pump system in a Canadian household. Energy Procedia, 30, 654-663. doi:10.1016/j.egypro.2012.11.074

[4] John A. Duffie, W. A. (2013). Solar Engineering of Thermal Processes:The Solar Constant (4nd ed. b.). New Jersey, Haboken, United States of America: John Wiley \& Sons.

[5] Warren M. Rohsenow, J. R. (1998). Handbook of Heat Transfer:Chapter 7.Radiation (Cilt 3). New-York: McGraw-Hill.

[6] K. Kadoya, N. Matsunaga, and A. Nagashima, Viscosity and Thermal Conductivity of Dry Air in the Gaseous Phase, Journal of Physical and Chemical Reference Data 14, 947 (1985)

[7] IAPWS R6-95 Revised Release on the IAPWS Formulation 1995 for the Thermodynamic Properties of Ordinary Water Substance for General and Scientific Use September 2018. (2018, 12 21). IAPWS.ORG. http://www.iapws.org/ relguide/IAPWS-95.html

[8] A. A. Ammar, K. S. (2019). Performance study on photovoltaic/thermal solar-assisted heat pump. Journal of Thermal Analysis and Calorimetry, 136(1), 79-87. doi:10.1007/ s10973-018-7741-6 
[9] Yessen SHAKIR, B. S. (2017). Numerical simulation of a heat pump assisted regenerative solar still with. Thermal Science, 21, 411-418.

[10] Evangelos Bellos, C. T. (2016). Energetic and financial evaluation of solar assisted heat pump space heating systems. Energy Conversion and Management, 120, 306-319.

[11] A. A. Ammar, K. S. (2019). Performance study on photovoltaic/thermal solar-assisted heat pump. Journal of Thermal Analysis and Calorimetry, 136(1), 79-87.

[12] Martin Kegela, J. T. (2012). Assessment of a solar assisted air source and a solar assisted. Energy Procedia, 30, 654-663.

[13] Xiangqiang Kong, P. S. (2018). Experimental studies of a variable capacity direct-expansion solar-assisted heat pump water heater in autumn and winter conditions. Solar Energy, 170, 352-357. https://doi.org/10.1016/j.solener.2018.05.081

[14] Peter Omojaro, C. B. (2013). Direct expansion solar assisted heat pumps. Renewable and Sustainable Energy Reviews, 22, 3345. doi:http://dx.doi.org/10.1016/j.rser.2013.01.029

[15] Mahmut Sami Buker, S. B. (2016). Solar assisted heat pump systems for low temperature water heating. RenewableandSustainableEnergyReviews, 55(2016), 399-413. http:// dx.doi.org/10.1016/j.rser.2015.10.157 